\title{
Hypersensitivity pneumonitis and metalworking fluids contaminated by
} mycobacteria

\author{
I. Tillie-Leblond*, F. Grenouillet", , G. Reboux", , S. Roussel ${ }^{\#, \text {, }}$, \\ B. Chouraki ${ }^{+}$, C. Lorthois ${ }^{+}$, J-C. Dalphin ${ }^{\S}$, B. Wallaert* and L. Millon ${ }^{\#, 9}$
}

ABSTRACT: Metalworking fluids (MWF) are responsible for hypersensitivity pneumonitis (HP). The aim of the present study was to identify the antigen $(\mathrm{Ag})$ responsible for MWF-associated HP, and to optimise serological diagnosis by definition of a threshold allowing discrimination between HP patients and asymptomatic exposed workers.

13 patients, who were workers at a car engine manufacturing plant, were suspected of MWF-associated HP. Microbial analysis of 83 used MWFs was carried out. Sera from 13 MWFassociated HP patients, 12 asymptomatic exposed workers and 18 healthy unexposed controls were tested to determine their immunological responses to three Ags, including Mycobacterium immunogenum.

M. immunogenum was identified in $40 \%$ of used fluids by culture and confirmed by DNA sequencing. The threshold for differentiating MWF-associated HP patients from asymptomatic exposed workers was five arcs of precipitation (sensitivity $77 \%$ and specificity $92 \%$ ), as determined by electrosyneresis (ES). Using ELISA methods with protein extract from M. immunogenum, a threshold leading to $92 \%$ sensitivity and $100 \%$ specificity was established.

The detection of specific antibodies against $M$. immunogenum $\mathrm{Ag}$ at high levels in case sera suggests that $M$. immunogenum-contaminated MWF is responsible for MWF-associated HP. To discriminate MWF-associated HP patients from asymptomatic exposed workers, we suggest a five-arc threshold for ES and a 1.6-AU threshold for ELISA methods.

KEYWORDS: Electrosyneresis, ELISA, hypersensitivity pneumonitis, metalworking fluid, Mycobacterium immunogenum, precipitins

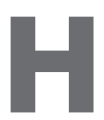

ypersensitivity pneumonitis (HP), or extrinsic allergic alveolitis, is caused by a wide range of antigens (Ags), including bacteria. Variability in its clinical presentation and the similarity of $\mathrm{HP}$ to other respiratory diseases can lead to under-diagnosis. Exposure to a relevant $\mathrm{Ag}$ is the most important predictor of HP [1]. Identification of the aetiological agent, and definition of a serological threshold for $\mathrm{HP}$ patients, asymptomatic exposed workers and healthy unexposed individuals are essential for the immunological diagnosis of HP. Exposure to metalworking fluids (MWF) is described in the literature as being responsible for $\mathrm{HP}$. In the USA, 1.2 million persons have been exposed to MWF. More than 100 cases of MWF-associated $\mathrm{HP}$ have been described in North America $[2,3]$. Rapidly growing mycobacteria (RGM) were considered to be the most likely aetiological agent of MWF-associated HP [4]. The French automobile industry has become concerned about the emergence of pathologies related to exposure to MWF.

13 workers from a car engine manufacturing plant in Lille, France, were referred to the local University Hospital as consecutive patients between 2004 and 2007. They suffered from respiratory symptoms consistent with HP and, after other causes had been ruled out, MWF-associated HP was suspected. The aim of the study was to identify the main Ag that may be involved with MWFassociated HP and to define a threshold to discriminate HP patients from asymptomatic exposed workers and healthy unexposed individuals. The following strategy was used: 1) cases of MWFassociated HP were confirmed by assessment of clinical, functional, radiological and bronchoalveolar lavage (BAL) data; 2) microbiological analysis of the MWF from the plant was performed; 3) Ag extracts from the most frequently isolated microorganisms (Mycobacterium immunogenum, Bacillus

\section{AFFILIATIONS}

*Dept of Pneumology, University of Lille, Lille,

\#Dept of Mycology, University Hospital of Besançon,

'CNRS-University of Franche-Comté ${ }^{\S}$ Dept of Pneumology, University Hospital of Besançon, Besançon, and ${ }^{+}$Dept of Occupational Medicine,

Douvrain, France.

CORRESPONDENCE

I. Tillie-Leblond Service de Pneumologie et d'Immuno-Allergologie Hôpital Calmette 1 bd Leclerca

CHRU

59037 Lille

France

E-mail: I-Tillie@chru-lille.fr

Received:

Dec 102009

Accepted after revision:

July 082010

First published online:

Aug 062010 
simplex and Fusarium solani) were performed; 4) the immunological response of the patients, asymptomatic controls and unexposed healthy controls to these antigens was assessed using electrosyneresis (ES) and ELISA methods; 5) a receiver operating characteristic (ROC) curve method was used to define a threshold between groups.

\section{METHODS}

\section{Subjects}

This study compared exposure and immunological response for MWF-associated HP cases $(n=13)$, asymptomatic exposed controls $(n=12)$ and unexposed healthy controls $(n=18)$. Informed written consent was obtained from all subjects. The protocol was approved by the local review board for research involving human subjects.

Case subjects were diagnosed with MWF-associated HP in our department (Dept of Pneumonology, University of Lille, Lille, France) according to clinical, biological and radiological criteria $[1,5,6]$ (medical investigations are given in the Results section).

Asymptomatic exposed controls were volunteers exposed to MWF at the same plant, in the same workshop and performing the same task as the MWH-associated HP cases. They were selected and examined by the occupational medical doctor when they were included in the study and again $1 \mathrm{yr}$ later.

The 18 unexposed healthy controls were volunteers recruited by health insurance company employees, living in urban areas (towns of $\geqslant 5,000$ residents). They were examined by the occupational medical doctor on an annual visit and gave responses to a medical questionnaire. The two control groups were similar to the MWF-associated HP patients group with respect to age ( \pm 5 yrs) and sex, and all were nonsmokers.

\section{Microbiological analyses}

Eight series of microbiological analyses were performed (one per month) between November 2006 and July 2007 on MWF from the machine shops where the 13 MWF-associated HP patients had been working (there were $>50$ workers per shop).

\section{Sampling}

Samples of $50 \mathrm{~mL}$ were taken from each vat of used MWF $(n=83)$, new MWF $(n=4)$, industrial water $(n=2)$, osmosed water $(n=5)$, ultrafiltered water $(n=2)$ and additives $(n=1)$ included in the preparation of MWF.

\section{Microbiological techniques}

MWF and other samples were analysed for bacteria, RGM, actinomycetes and fungi on three different solid media: Actinomycetes Difco ${ }^{\mathrm{TM}}$ (Becton Dickinson ${ }^{\circledR}$, Cockeysville, MD,

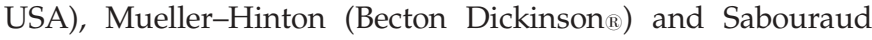
chloramphenicol agar (Bio-Rad $₫$, Marnes la Coquette, France). Petri dishes plated with $0.1 \mathrm{~mL}$ of one of the samples were incubated at $30^{\circ} \mathrm{C}$ for 3 weeks. Colonies of bacteria and fungi were identified and numerated. The limit of detection was 10 colony-forming units $(\mathrm{CFU}) \cdot \mathrm{mL}^{-1}$.

Screening for M. immunogenum was performed by PCRrestriction analysis of heat shock protein ( $h s p$ ) genes, using a combination of patterns obtained after digestion with three different enzymes, as described previously (HhaI, HinfI and
MspI) [4], and compared to five reference RGM strains, including $M$. immunogenum.

Identification of suspected $M$. immunogenum isolates was confirmed by PCR amplification followed by sequencing of $h s p$ and RNA polymerase (rpo) genes, using previously described PCR methods [7, 8].

Mycobacteria were identified by using Basic Local Alignment Search Tool (BLAST) searches of their sequences compared with sequences in the GenBank database (www.ncbi.nlm.nih. gov/BLAST). Identification of species was determined by a similarity of both $h s p$ and rpo genes $>97 \%$ [9].

\section{Immunological methods}

\section{Strains, culture and Ag production}

One strain of $M$. immunogenum, isolated during the first survey of MWF samples from the car engine manufacturing plant, was cultured on Mueller-Hinton plates at $30^{\circ} \mathrm{C}$ for 1 week to obtain a microbial mass. The structures of $M$. immunogenum were recovered by scraping and filtration. Two M. immunogenum Ag extracts were produced: a total aqueous lyophilised extract (somatic Ag) used for ES on cellulose acetate [10,11] and a protein extract used for ELISA tests [12].

Somatic Ag extracts from M. immunogenum, F. solani and B. simplex were produced as follows: strains were cultured on Mueller-Hinton (for M. immunogenum and B. simplex) or Dichloran-glycerol 18 agar (Oxoid; Unipath, Basingstoke, UK) with $0.5 \%$ chloramphenicol (Merck ${ }_{\AA}$, Darmstat, Germany) (for F. solani) culture media for 2 weeks, crushed with an ULTRATURRAX $_{\circledR}$ (IKA Labortechnik, Staufen, Germany), sonicated, extracted overnight in $\mathrm{NH}_{4} \mathrm{CO}_{3}\left(6 \mathrm{~g} \cdot \mathrm{L}^{-1}\right)$ at $4{ }^{\circ} \mathrm{C}$, centrifuged at $1,580 \times g(13,000 \mathrm{rpm})$, ultrafiltered with a Centricon 10 (Amicon Millipore ${ }^{\circledR}$, Saint Quentin en Yvelines, France), lyophilised and resuspended to a concentration of $100 \mathrm{mg} \cdot \mathrm{mL}^{-1}$ in sterile distilled water.

Protein extract from M. immunogenum was produced as follows: mycobacteria from 20 densely grown MuellerHinton plates were first suspended in $60 \mathrm{~mL}$ of $1 \mathrm{M}$ tris(hydroxymethyl)-aminomethane (Tris)- $\mathrm{HCl}$ buffer, $\mathrm{pH} 7.5$, supplemented with protease inhibitors $(1 \mathrm{mM}$ phenylmethylsulfonylfluoride, $1 \mathrm{mM}$ phenanthroline and $1 \mu \mathrm{M}$ pepstatin; Sigma-Aldrich $_{\mathbb{R}}$, St Louis, MO, USA). The mixture was lysed by grinding with an ULTRA-TURRAX ${ }_{\circledR}$ device then sonication using five cycles of alternate $1 \mathrm{~min}$ pulsing and $1 \mathrm{~min}$ chilling on ice. Cell fragments were eliminated by two subsequent centrifugations for $3 \mathrm{~min}$ at $1,580 \times g(10,000 \mathrm{rpm})$ at $4^{\circ} \mathrm{C}$, recovering the supernatant after each spin. $100 \mu \mathrm{L} \quad 0.1 \%$ deoxycholic acid solution (Sigma-Aldrich ${ }_{\circledR}$ ) was added per millilitre of supernatant and the preparation was incubated for $5 \mathrm{~min}$ at room temperature. Proteins were pelleted on ice for 15 min with $70 \mu \mathrm{L} 0.6 \mathrm{M}$ trichloroacetic acid (Sigma-Aldrich ${ }^{\circledR}$ ) per millilitre of supernatant. Precipitated proteins were subsequently pelleted by centrifugation $\left(4^{\circ} \mathrm{C}\right.$ for $15 \mathrm{~min}$ at $30,000 \times g$ using a JA 20.1 rotor (Beckman Coulter ${ }^{\circledR}$, Roissy, France). Protein extracts were purified with an SDS-PAGE Clean-Up Kit (Roche Diagnostics ${ }^{\circledR}$, Basel, Switzerland) as recommended by the manufacturer. Protein concentrations of the purified extracts were determined using the DC Protein

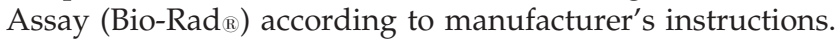




\section{ES on cellulose acetate}

Samples of $15 \mu \mathrm{L}$ of each serum were placed on three spots on the anode side and a $15-\mu \mathrm{L}$ line of somatic antigen was placed on the cathode side $3.5 \mathrm{~cm}$ from the first deposit (fig. 1). The samples were washed and stained after 150 min of migration in a $90 \mathrm{mV}$ current. The number of arcs was determined for each serum and results were analysed by ROC curve to determine a threshold between groups [10].

\section{ELISA}

As described previously [10, 12], 96-well plates (PolySorp Immunomodule; Nalge Nunc $\mathbb{}$, Rochester, NY, USA) were coated with $200 \mu \mathrm{L} 1 \mu \mathrm{g} \cdot \mathrm{mL}^{-1}$ protein $\mathrm{Ag}$ solution in $50 \mathrm{mM}$ $\mathrm{K}_{2} \mathrm{HPO}_{4}$ buffer (Sigma-Aldrich ${ }^{\circledR}$ ), $\mathrm{pH} 8.5$, at $4^{\circ} \mathrm{C}$ for $48 \mathrm{~h}$. Excess binding sites were blocked at $37^{\circ} \mathrm{C}$ for $1 \mathrm{~h}$ with $250 \mu \mathrm{L}$ of $50 \mathrm{mM} \mathrm{NaH}{ }_{2} \mathrm{PO}_{4}$ buffer (Sigma-Aldrich ${ }$ ) containing $0.5 \%$ bovine serum albumin (Sigma-Aldrich ${ }_{\mathbb{R}}$ ) and $60 \mathrm{~g} \cdot \mathrm{L}^{-1}$ sorbitol

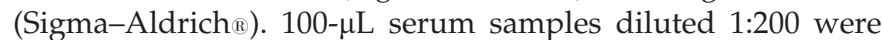
added in triplicate to all wells. The plates were incubated at $37^{\circ} \mathrm{C}$ for $1 \mathrm{~h}$ under constant agitation. Plates were washed four times with washing buffer (100 mM Tris- $\mathrm{HCl}, \mathrm{pH} 7.5 ; 0.25 \%$ Tween). Next, $100 \mu \mathrm{L}$ peroxidase-conjugated goat anti-human immunoglobulin $(\mathrm{Ig}) \mathrm{G}$ diluted 1:4,000 (Sigma-Aldrich ${ }_{\mathbb{R}}$ ) were added to all wells and the plates were incubated at $37^{\circ} \mathrm{C}$ for $1 \mathrm{~h}$. The washing procedure was repeated once and $100 \mu \mathrm{L}$ of 3,3',5,5'-tetramethylbenzidine solution (TMB One-Step Substrate System; RD Biotech ${ }_{\mathbb{}}$, Besançon, France) at room temperature were added to the wells for $10 \mathrm{~min}$. To stop the colour reaction, $100 \mu \mathrm{L}$ of an acid solution $\left(0.5 \mathrm{~N} \mathrm{H}_{2} \mathrm{SO}_{4}\right)$ were added. Wells were read spectrophotometrically at $450 \mathrm{~nm}$ (Titertek Multiskan ${ }^{\circledR}$, Huntsville, AL, USA) and the results were expressed in arbitrary units.

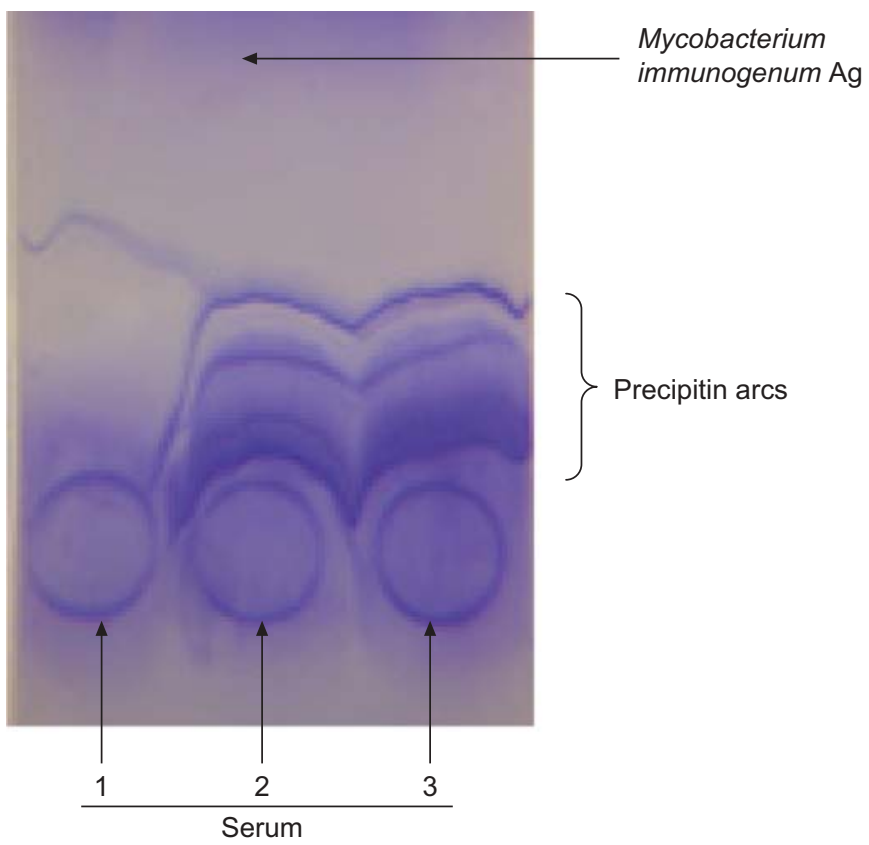

FIGURE 1. Electrosyneresis with Mycobacterium immunogenum antigen (Ag) against three sera from metalworking fluid-associated hypersensitivity pneumonitis cases. Serum 1: case 8 (three arcs); serum 2: case 11 (seven arcs; from May 2007); serum 3: case 11 (seven arcs; from September 2007).

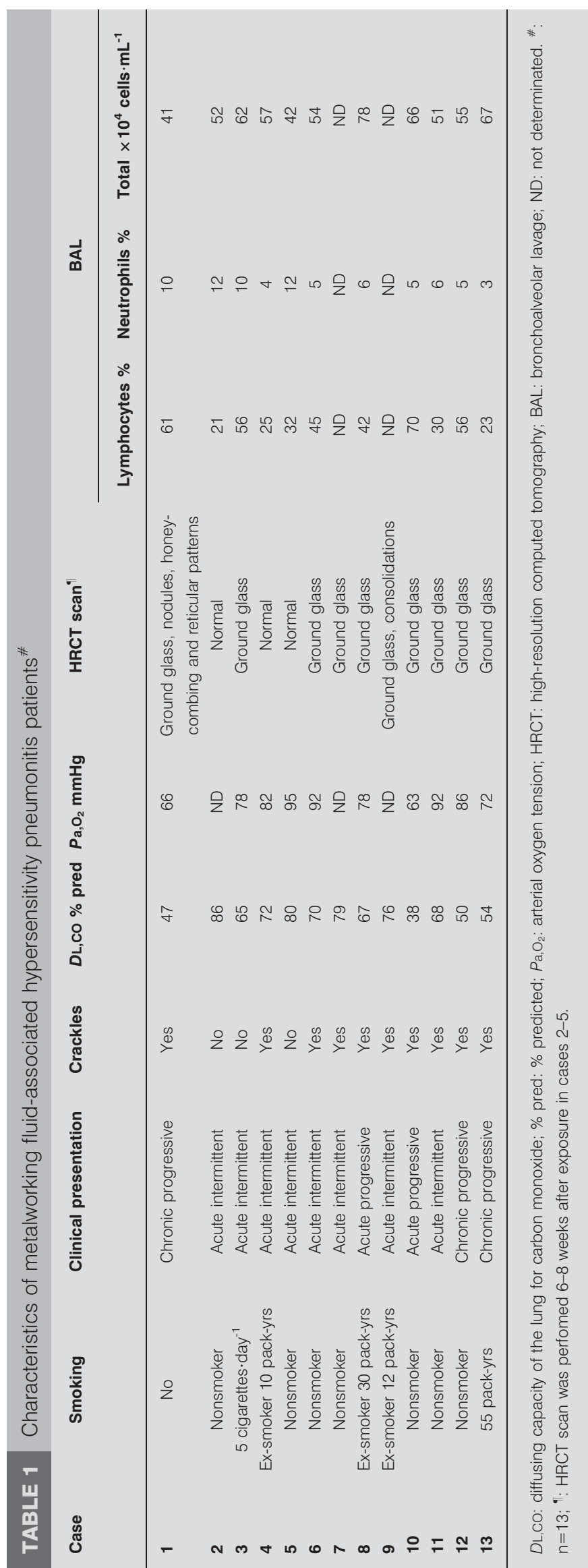




\section{Statistical analysis}

Concentrations of serum and Ags used were preliminarily determined by dilution assays. Sera were deposited on plates in triplicate and variation coefficients corresponding to standard deviation divided by mean of the triplicate were calculated. If a variation coefficient was $>15 \%$, the serum was tested again. This was done only for optical densities $>0.050$. A reference serum, which was a pool of two sera from nonexposed subjects, was deposited on each plate in triplicate. The ratio the mean of the triplicate for the tested serum to the mean of the triplicate for reference pool was used for analysis. This ratio was expressed in arbitrary units. ROC analysis was chosen to compare the diagnostic performance of immunological tests. The optimum cut-off level was determined with sensitivity and specificity tables provided by STATA Software Release 9 (StataCorp LP, College Station, TX, USA). The value selected corresponded to the maximum sensitivity and specificity. The area under the ROC curve indicated the discriminating capacity of the Ags. A high value for the area under the curve (AUC) indicated good sensitivity and specificity. AUC $<0.5$ indicated that the test could not discriminate patients from exposed controls.

A bilateral, unpaired t-test was used to compare the ELISA and ES results (in arbitrary units and number of precipitin arcs, respectively) of patient and control groups. STATA Software Release 9 was also used for this test.

\section{RESULTS}

\section{Subjects}

MWF-associated HP was diagnosed in 13 male patients referred to the University Hospital of Lille between January 2004 and September 2007. Their mean age was 46.3 yrs (range 34-56 yrs). All had been chronically exposed to MWF, with a mean duration of exposure of 9 yrs (range 3-20 yrs). 12 patients were workers on a car engine assembly line coating metal parts with semisynthetic MWF; one patients had been intermittently exposed to MWF once or twice a day when supervising the car engine machine shops. All 13 MWFassociated HP patients showed significant improvement of clinical symptoms after stopping work for 1 month. Subjects with MWF-associated HP had clinical symptoms compatible with HP (crackles, cough and/or fever, loss of weight, and asthenia), low diffusing capacity of the lung for carbon monoxide (DL,CO), and lymphocytosis on BAL $(>20 \%)$.
Radiographic imaging was performed (high-resolution computed tomography (HRCT) lung scans) in order to assess nodules, ground-glass opacities, septal thickening, consolidation, honeycombing, traction bronchiectasis and bronchiolectasis, reticular pattern, pleural effusion, and adenopathy $[1,5,6]$. HRCT was performed as soon as possible after working periods. In cases 2, 3, 4 and 5, HRCT was performed from 6-9 weeks after exposure. HRCT was normal in three cases (cases 2, 4 and 5). For these three patients, other criteria for HP diagnosis were present. Cases that had suggestive HRCT were classified as confirmed patients $(n=10)$ and those who did not were classified as probable patients $(n=3)$. DL,CO was measured and BAL carried out. Serological analysis of sera was performed routinely to look for Aspergillus fumigatus and Pseudomonas antibodies, by ES and ELISA. All were negative. Consequently serological research was extended to other Ags effectively present in MWF. The clinical characteristics of the MWF-HP patients are reported table 1.

Exposed controls were all nonsmoking workers with no underlying respiratory disease. All were asymptomatic: they had no crackles, and lung function and DL,CO were normal (HRCT scan and BAL were not performed).

Unexposed controls were also all nonsmoking workers. They had no crackles at auscultation and gave negative responses to question about respiratory symptoms.

\section{MWF microbiological results}

M. immunogenum was identified in 33 used MWF samples from the car engine machine shops. No M. immunogenum was found in any samples of osmotically ultrafiltered or industrial water, or additives. All samples from new oil were sterile. Microbial contamination was found in $74(89 \%)$ out of 83 samples of used MWF.

M. immunogenum was isolated from $33(40 \%)$ out of 83 used MWF samples. Concentration of $M$. immunogenum varied from 2 to $>4,000 \mathrm{CFU} \cdot \mathrm{mL}^{-1}$ (mean $847 \mathrm{CFU} \cdot \mathrm{mL}^{-1}$ ). Bacillus spp. (including B. simplex) were isolated from 35 (42\%) out of 83 of samples. Gram-negative bacteria (excluding Pseudomonas spp.) were present in $<12 \%$ of used MWF samples. Fungi were isolated in nine $(11 \%)$ out of 83 samples of used MWF, mainly F. solani (three (4\%) out of 83 samples) and Aspergillus spp. (five (6\%) out of 83 samples; A. fumigatus and Aspergillus

TABLE 2 Isolation frequencies for the microorganisms in metalworking fluid (MWF), water and additive samples ${ }^{\#}$

\begin{tabular}{|c|c|c|c|c|c|c|c|c|c|}
\hline Sample type & $\begin{array}{l}\text { Positive } \\
\text { samples }\end{array}$ & $\begin{array}{c}\text { Sterile } \\
\text { samples }\end{array}$ & $\begin{array}{l}\text { Mycobacterium } \\
\text { immunogenum }\end{array}$ & $\begin{array}{l}\text { Mycobacterium } \\
\text { Ilatzerense }\end{array}$ & $\begin{array}{l}\text { Aspergillus } \\
\text { fumigatus }\end{array}$ & $\begin{array}{l}\text { Fusarium } \\
\text { solani }\end{array}$ & $\begin{array}{l}\text { Other } \\
\text { fungi" }\end{array}$ & $\begin{array}{l}\text { Bacillus } \\
\text { spp. }\end{array}$ & $\begin{array}{c}\text { Other } \\
\text { bacteria }^{+}\end{array}$ \\
\hline Additive & 0 & 1 & 0 & 0 & 0 & 0 & 0 & 0 & 0 \\
\hline Used MWF & 74 & 9 & 33 & 0 & 4 & 3 & 3 & 35 & 9 \\
\hline Industrial water & 2 & 0 & 0 & 0 & 0 & 0 & 0 & 0 & 2 \\
\hline Ultrafiltered water & 2 & 0 & 0 & 0 & 0 & 0 & 0 & 0 & 2 \\
\hline
\end{tabular}


flavus). In one case, $A$. fumigatus was isolated with Curvularia lunata in the same sample

A polymorphic bacterial flora (including RGM in one case, i.e. Mycobacterium llatzerense) was found in samples of osmosed water, but no M. immunogenum was isolated from these or from the washing effluents. Microbiological results by culture method are presented in table 2.

\section{Precipitins and IgG against M. immunogenum, F. solani and B. simplex Ags}

ES was performed to detect precipitin arcs against M. immunogenum, F. solani and B. simplex Ags, corresponding to microorganisms present in fluid samples (table 3). For M. immunogenum Ag, the number of precipitin arcs was significantly higher for MWF-associated HP patients than for the asymptomatic exposed controls (t-test $p=0.002$ ). A five precipitin arcs threshold (superior or equal) gave AUC 0.853 (95\% CI $0.68-1.00), 77 \%$ sensitivity and $92 \%$ specificity. For

\begin{tabular}{|c|c|}
\hline TABLE 3 & $\begin{array}{l}\text { Number of precipitin arcs for three antigens } \\
\text { (Ags) by electrosyneresis in metalworking fluid- } \\
\text { associated hypersensitivity pneumonitis patients } \\
\text { and exposed controls }\end{array}$ \\
\hline \multirow[t]{2}{*}{ Case } & Precipitin arcs $n$ \\
\hline & M. immunogenum Ag \\
\hline
\end{tabular}

\begin{tabular}{|c|c|c|c|}
\hline \multicolumn{4}{|c|}{ Patients } \\
\hline 1 & 9 & 0 & 1 \\
\hline 2 & 7 & 0 & $c$ \\
\hline 3 & 11 & 2 & $c$ \\
\hline 4 & 5 & 0 & 2 \\
\hline 5 & 11 & 0 & 2 \\
\hline 6 & 12 & 0 & 1 \\
\hline 7 & 11 & 0 & $c$ \\
\hline 8 & 3 & 0 & 2 \\
\hline 9 & 4 & 0 & 2 \\
\hline 10 & 5 & 0 & $c$ \\
\hline 11 & 7 & 4 & 3 \\
\hline 12 & 8 & 1 & 3 \\
\hline 13 & 1 & 0 & $c$ \\
\hline \multicolumn{4}{|c|}{ Exposed controls } \\
\hline 1 & 12 & 2 & 1 \\
\hline 2 & 0 & 0 & 1 \\
\hline 3 & 3 & 0 & 4 \\
\hline 4 & 1 & 0 & 3 \\
\hline 5 & 0 & 1 & c \\
\hline 6 & 1 & 0 & $c$ \\
\hline 7 & 4 & 0 & $c$ \\
\hline 8 & 4 & 0 & c \\
\hline 9 & 4 & 1 & $c$ \\
\hline 10 & 1 & 1 & 1 \\
\hline 11 & 0 & 0 & $c$ \\
\hline 12 & 0 & 0 & 2 \\
\hline
\end{tabular}

M. immunogenum: Mycobacterium immunogenum; F. solani: Fusarium solani; B. simplex: Bacillus simplex.
F. solani and B. simplex Ags, the number of precipitin arcs was not significantly higher for MWF-associated HP patients than for asymptomatic exposed controls (t-test $\mathrm{p}=0.76$ and $\mathrm{p}=0.65$, respectively). AUCs were 0.468 (95\% CI 0.28-0.65) for F. solani $\mathrm{Ag}$ and 0.571 (95\% CI 0.35-0.79) for B. simplex Ag. ROC curves are presented in figure 2.

The mean $\pm \mathrm{SD}$ M. immunogenum-specific IgG, as measured by ELISA, was significantly higher in patients $(2.6 \pm 1.2 \mathrm{AU})$ than in asymptomatic exposed controls $(1.1 \pm 0.3 \mathrm{AU}$; t-test $\mathrm{p}<0.001)$ or unexposed controls $(1 \pm 0.4$ AU; t-test $\mathrm{p}<0.001)$. The difference between mean IgG for exposed and unexposed controls was not significant $(\mathrm{t}$-test $\mathrm{p}=0.29)$.

ES results are reported in table 3 and comparison of performances for three antigens by ROC curves were given in fig. 2. Performances for ES and ELISA using M. immunogenum Ags were reported in table 4 with two different comparisons: results for asymptomatic exposed controls were compared the first with results for all patients with MWFassociated HP (probable and confirmed patients; $n=13$ ) and secondly with results for patients with abnormal HRCT scan (confirmed patients; $n=10$ ). Determinate thresholds with ES and ELISA were equal for both comparisons. Performances of ELISA (sensitivity and specificity) were similar if we considered probable or confirmed patients. Sensibility and likelihood ratio of positive test for ES were slightly decreased when we considered only confirmed patients instead of all patients. AUCs were 0.853 (95\% CI 0.681-1.000) for ES and 0.936 (95\% CI $0.810-1.000)$ for ELISA in considering all patients, and were 0.833 (95\% CI 0.615-0.955) for ES and 0.917 (95\% CI $0.718-0.988)$ for ELISA when considering confirmed patients only (figs 3 and 4).

\section{DISCUSSION}

Our study reports an outbreak of 13 cases of MWF-associated $\mathrm{HP}$ arising at a single automobile factory between 2004 and 2007. To our knowledge, this is the second such episode of grouped cases arising in an automobile factory in Europe. The study demonstrates that $M$. immunogenum was identified in MWF even though this species is weakly susceptible to common antiseptics. The detection of specific precipitins for

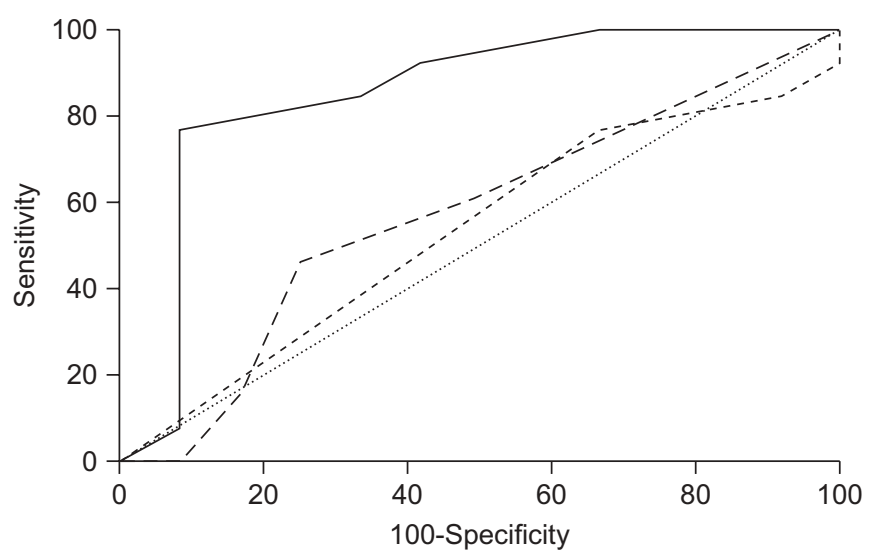

FIGURE 2. Receiver operating characteristic curve comparing Mycobacterium immunogenum (-), Fusarium solani (----) and Bacillus simplex $(---)$ in electrosyneresis 


\begin{tabular}{|c|c|c|c|c|c|c|c|c|c|}
\hline TABLE & $\begin{array}{l}\text { Paran } \\
\text { expos }\end{array}$ & $\begin{array}{l}\text { eters for imm } \\
\text { d controls, }\end{array}$ & $\begin{array}{l}\text { nological tes } \\
\text { id confirmed }\end{array}$ & $\begin{array}{l}\text { s using antig } \\
\text { satients to ex }\end{array}$ & $\begin{array}{l}\text { ns of Mycob } \\
\text { osed contro }\end{array}$ & sterium imm & logenum co & baring total $p$ & tients to \\
\hline \multirow[t]{2}{*}{ Method } & \multirow[t]{2}{*}{ Threshold } & \multicolumn{4}{|c|}{ Total patients ${ }^{\#}$ versus exposed controls } & \multicolumn{4}{|c|}{ Confirmed patients ${ }^{+}$versus exposed controls ${ }^{*}$} \\
\hline & & Sensitivity \% & Specificity \% & LR+ & LR- & Sensitivity \% & Specificity \% & LR+ & LR- \\
\hline ES & 5 arcs & $77(46-94)$ & $92(60-99)$ & $9.2(1.4-61.7)$ & $0.2(0.1-0.7)$ & $70(35-92)$ & $92(60-99)$ & $8.7(1.2-57.3)$ & $0.3(0.1-0.9)$ \\
\hline
\end{tabular}

M. immunogenum in sera enabled a strong link to be established between MWF-associated HP and M. immunogenum-contaminated MWF. A threshold to differentiate MWF-associated HP cases from asymptomatic exposed controls is suggested.

Working procedures to limit exposure to MWF are particularly developed in the USA [1, 13], where most MWF-associated HP cases have been described. Large volumes of MWF are used in manufacturing industries for cooling and lubrication of metal pieces and tools during machining, especially in the manufacture of automotive parts. Respiratory manifestations have been described, such as an increase in bronchial hyperresponsiveness, asthma [14] and HP [2, 15-17]. MWF may be toxic in various ways, for example by inhalation of toxic particles, endotoxins [18, 19] or a complex population of microbial flora [20]. BERNSTEIN et al. [15] reported HP associated with the use of semisynthetic MWF, called "machine operator's lung". Aerobic Gram-negative rods, such as $P$. aeruginosa and Acinetobacter [13], fungi, and members of the Mycobacterium chelonae complex, including Mycobacterium abscessus, $M$. chelonae and M. immunogenum, have been identified in MWF [21-24]. Mycobacteria and Pseudomonas may also be identified in MWF by real-time PCR assays [25]. The role of microorganisms in the induction of manifestation of $\mathrm{HP}$ is commonly established by precipitins or specific immunoglobulin (IgG) response. Precipitins against Pseudomonas fluorescens were observed in serum from six workers from a plant in 1992 [15]. DAWKINs et al. [26]. described 12 cases (2003-2004) of

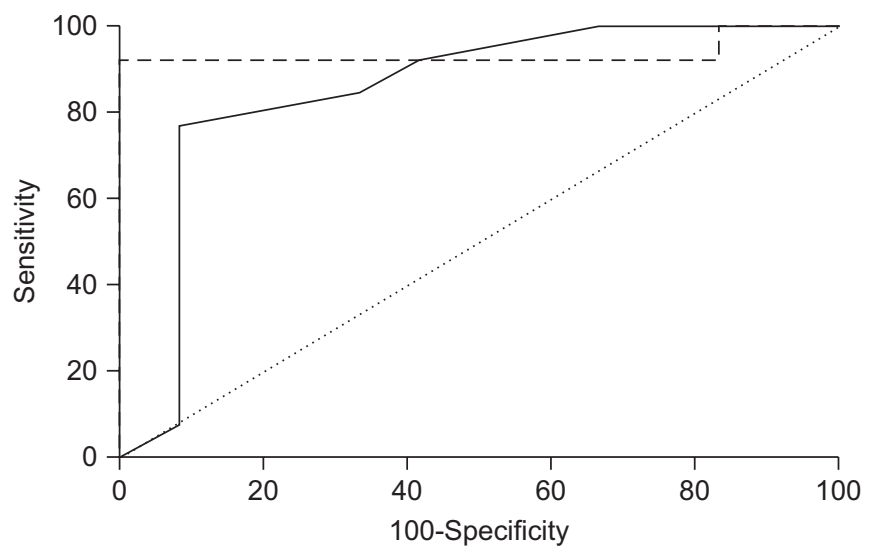

FIGURE 3. Receiver operating characteristic curves comparing electrosyneresis (-) and ELISA (----) results with Mycobacterium immunogenum antigen for all patients $(n=13)$ and exposed controls.
MWF-associated HP who had precipitins against Acinetobacter and Ochrobactrum, but precipitins were also present in a similar proportion of exposed control workers without disease at the same plant. Many of MWF-associated HP cases were linked to MWF containing nontuberculous RGM [21, 24, 27-29]. WILSON et al. [4] and WALLACE et al. [24] showed that 95\% of mycobacterial isolates recovered from industrial MWF in plants with cases of machinist HP belong to $M$. immunogenum. MWF containing M. immunogenum induced granulomatous lung lesions and peribronchiolar lymphocytosis consistent with HP in laboratory mice [30]. The present study brings additional evidence for the role of M. immunogenum in HP related to MWF exposure in humans. Gram-negative bacteria, such as Pseudomonas, are often predominant organisms in MWF [31-33]. In our study, predominant bacteria were M. immunogenum and Bacillus spp., whereas Gramnegative bacteria were present in $<12 \%$ of used MWF.

Identification of pathogens in MWF and/or specific antibodies directed against the pathogen is essential for HP diagnosis. In the present work, we also suggested a threshold for M. immunogenum precipitins to differentiate MWF-associated HP cases from asymptomatic exposed individuals. The ELISA method seems to be the stronger test to differentiate MWFassociated HP cases from asymptomatic exposed individuals in this series of experiments. This difference may be related to the Ag extracts used, which were different in the ELISA and ES experiments (protein extract was used for ELISA). Previous

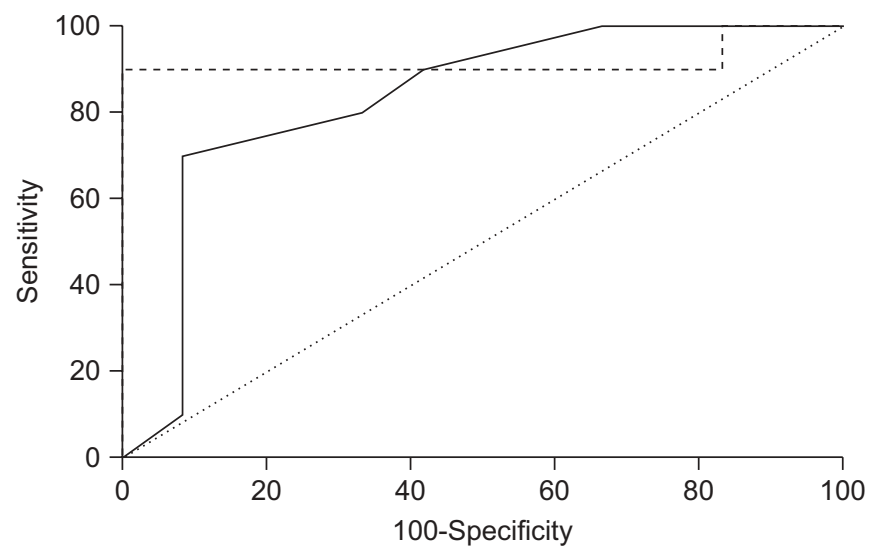

FIGURE 4. Receiver operating characteristic curves comparing electrosyneresis (-) and ELISA (----) results with Mycobacterium immunogenum antigen for confirmed patients $(n=10)$ and exposed controls. 
studies have also suggested serological scores or thresholds to differentiate HP from exposed asymptomatic persons in farmer's lung and bird breeder's lung [34-36].

Without specific procedures for prevention of MWF-associated $\mathrm{HP}$ and identification of cases by occupational physicians, there is a risk that only severe forms of the disease will be diagnosed. At the time of writing, 12 clustered cases have been described in Europe, in the UK [26], and 100 cases in USA [2, 3]. The National Institute of Occupational Safety and Health (NIOSH) published a recommended exposure limit (REL) for MWF in 1998 to prevent respiratory disorders associated with industrial lubricants [37]. The REL is $0.4 \mathrm{mg} \cdot \mathrm{m}^{-3}$ [37]. COHEN et al. [37] recently suggested that manufacturing companies failed to control the level of exposure to $<1 \mathrm{mg} \cdot \mathrm{m}^{-3}$ and that protective equipment or medical surveillance programmes are insufficient. GUPTA and ROSENMAN [38] point out that HP arose from environments with exposures well below the Occupational Safety and Health Administration (OSHA) permissible exposure limit for MWF and, in one case, from exposures well below the NIOSH REL. We deduce that particular levels are insufficient to assess whether or not a risk of HP exists. In our opinion, microbiological surveys, especially with real-time PCR to assess presence or absence of M. immunogenum, are needed in order to evaluate HP risk in a plant.

Implementation of specific medical surveillance programmes is essential in manufacturing plants. Factors associated with reduced aerosol exposure included machining aluminium, milling, the height of the machine shop roof and the presence of mechanical machine shop ventilation [39].

\section{Conclusion}

The presence of large amounts of M. immunogenum in $>40 \%$ of used MWF samples taken from several machine shops at the same manufacturing plant and the detection of specific precipitins against $M$. immunogenum $\mathrm{Ag}$ in sera suggest that M. immunogenum-contaminated MWF is responsible for MWFassociated HP. The threshold of five arcs by ES differentiates MWF-associated HP cases from asymtomatic exposed controls with a sensitivity of $77 \%$ and a specificity of $92 \%$. An ELISA method using protein Ag improves this discrimination (sensitivity $92 \%$ and specificity 100\%). Clearly, any investigation of contamination of MWF in a manufacturing plant must include identification and quantification of RGM, with special focus on $M$. immunogenum. The introduction of a prevention programme of regular sampling and analysis the MWF, adequate protective action, and medical surveillance of exposed workers may prevent or minimise HP disease.

Future studies involving several plants with new cases of MWF-associated HP are needed to confirm that the thresholds are able to discriminate between patients and exposed controls.

\section{STATEMENT OF INTEREST}

None declared.

\section{REFERENCES}

1 Lacasse Y, Selman M, Costabel U, et al. Clinical diagnosis of hypersensitivity pneumonitis. Am J Respir Crit Care Med 2003; 168: 952-958.
2 From the Centers for Diseases Control and Prevention. Respiratory illness in workers exposed to metalworking fluid contaminated with nontuberculous mycobacteria: Ohio, 2001. JAMA 2002; 287: 3073-3074.

3 Kreiss K, Cox-Gaenser J. Metalworking-fluid-associated hypersensitivity pneumonitis: a workshop summary. Am J Ind Med 1997; 423-432.

4 Wilson RW, Steingrube VA, Böttger EC, et al. Mycobacterium immunogenum sp. nov., a novel species related to Mycobacterium abscessus and associated with clinical disease, pseudo-outbreaks and contaminated metalworking fluids: an international cooperative study on mycobacterial taxonomy. Int J Syst Evol Microbiol 2001; 51: 1751-1764.

5 Ismail T, McSharry C, Boyd G. Extrinsic allergic alveolitis. Respirology 2006; 11: 262-268.

6 Bourke SJ, Dalphin JC, Boyd G, et al. Hypersensitivity pneumonitis: current concepts. Eur Respir J 2001; 18: Suppl.32 81s-92s.

7 Lee H, Park HJ, Cho SN, et al. Species identification of mycobacteria by PCR-restriction fragment length polymorphismm of the rpoB gene. J Clin Microbiol 2000; 38: 2966-2971.

8 Telenti A, Marchesi F, Balz M, et al. Rapid identification of mycobacteria to the species level by polymerase chain reaction and restriction enzyme analysis. J Clin Microbiol 1993; 31: 175-178.

9 Adékambi T, Colson P, Drancourt M. rpoB-based identification of nonpigmented and late-pigmenting rapidly growing mycobacteria. J Clin Microbiol 2003; 41: 5699-5708.

10 Reboux G, Piarroux R, Roussel S, et al. Assessment of four serological techniques in the immunological diagnosis of farmers' lung disease. J Med Microbiol 2007; 56: 1317-1321.

11 Reboux G, Piarroux R, Mauny F, et al. Role of molds in farmer's lung disease in Eastern France. Am J Respir Crit Care Med 2001; 163: 1534-1539.

12 Roussel S, Reboux G, Rognon B, et al. Comparison of three antigenic extracts of Eurotium amstelodami in serological diagnosis of farmer's lung disease. Clin Vaccine Immunol 2010; 17: 160-167.

13 Gauthier SL. Metalworking fluids: oil mist and beyond. Appl Occup Environ Hyg 2003; 18: 818-824.

14 Kennedy SM, Chan-Yeung M, Teschke K, et al. Change in airway responsiveness among apprentices exposed to metalworking fluids. Am J Respir Crit Care Med 1999; 159: 87-93.

15 Bernstein DI, Lummus ZL, Santilli G, et al. Machine operator's lung. A hypersensitivity pneumonitis disorder associated with exposure to metalworking fluid aerosols. Chest 1995; 108: 636-641.

16 Bracker A, Storey E, Yang C, et al. An outbreak of hypersensitivity pneumonitis at a metalworking plant: a longitudinal assessment of intervention effectiveness. Appl Occup Environ Hyg 2003; 18: 96-108.

17 Piacitelli GM, Sieber WK, O’Brien DM, et al. Metalworking fluid exposures in small machine shops: an overview. AIHAJ 2001; 62: 356-370.

18 Abrams L, Seixas N, Robins $\mathrm{T}$, et al. Characterization of metalworking fluid exposure indices for a study of acute respiratory effects. Appl Occup Environ Hyg 2000; 15: 492-502.

19 Thorne PS, DeKoster JA. Pulmonary effects of machining fluids in guinea pigs and mice. Am Ind Hyg Assoc J 1996; 57: 1168-1172.

20 Wang $\mathrm{H}$, Reponen $\mathrm{T}$, Lee SA, et al. Size distribution of airborne mist and endotoxin-containing particles in metalworking fluid environments. J Occup Environ Hyg 2007; 4: 157-165.

21 Moore JS, Christensen M, Wilson RW, et al. Mycobacterial contamination of metalworking fluids: involvement of a possible new taxon of rapidly growing mycobacteria. AIHAJ 2000; 61: 205-213.

22 Khan IU, Selvaraju SB, Yadav JS. Occurrence and characterization of multiple novel genotypes of Mycobacterium immunogenum and Mycobacterium chelonae in metalworking fluids. FEMS Microbiol Ecol 2005; 54: 329-338. 
23 Trout D, Weissman DN, Lewis D, et al. Evaluation of hypersensitivity pneumonitis among workers exposed to metal removal fluids. Appl Occup Environ Hyg 2003; 18: 953-960.

24 Wallace Jr RJ, Zhang Y, Wilson RW, et al. Presence of a single genotype of the newly described species Mycobacterium immunogenum in industrial metalworking fluids associated with hypersensitivity pneumonitis. Appl Environ Microbiol 2002; 68: 5580-5584.

25 Khan IU, Yadav JS. Real-time PCR assays for genus-specific detection and quantification of culturable and non-culturable mycobacteria and pseudomonads in metalworking fluids. Mol Cell Probes 2004; 18: 67-73.

26 Dawkins $\mathrm{P}$, Robertson A, Robertson W, et al. An outbreak of extrinsic alveolitis at a car engine plant. Occup Med (Lond) 2006; 56: 559-565.

27 Beckett W, Kallay M, Sood A, et al. Hypersensitivity pneumonitis associated with environmental mycobacteria. Environ Health Perspect 2005; 113: 767-770.

28 Weiss L, Pue C, Lewis R, et al. Respiratory illness in workers exposed to metalworking fluid contaminated with nontuberculous mycobacteria: Ohio 2001. MMWR Morb Mortal Wkly Rep 2002; 51: 349-351.

29 Shelton BG, Flanders WD, Morris GK. Mycobacterium sp. as a possible cause of hypersensitivity pneumonitis in machine workers. Emerg Infect Dis 1999; 5: 270-273.

30 Thorne PS, Adamcakova-Dodd A, Kelly KM, et al. Metalworking fluid with mycobacteria and endotoxin induces hypersensitivity pneumonitis in mice. Am J Respir Crit Care Med 2006; 173: 759-768.
31 Veillette M, Thorne PS, Gordon T, et al. Six month tracking of microbial growth in a metalworking fluid after system cleaning and recharging. Ann Occup Hyg 2004; 48: 541-546.

32 Cyprowski M, Piotrowska M, Zakowska Z, et al. Microbial and endotoxin contamination of water-soluble metalworking fluids. Int J Occup Med Environ Health 2007; 20: 365-371.

33 Lewis D, Janotka E, Whitmer M, et al. Detection of microbial antigens in metal working fluids. Int Biodet Biodeg 2001; 47: 89-94.

34 Fenoglio CM, Reboux G, Sudre B, et al. Diagnostic value of serum precipitins to mould antigens in active hypersensitivity pneumonitis. Eur Respir J 2007; 29: 706-712.

35 Reynaud C, Slosman DO, Polla BS. Precipitins in bird breeder's disease: how useful are they? Eur Respir J 1990; 3: 1155-1161.

36 Lopata AL, Schinkel M, Potter PC, et al. Qualitative and quantitative evaluation of bird-specific IgG antibodies. Int Arch Allergy Immunol 2004; 134: 173-178.

37 Cohen H, White EM. Metalworking fluid mist occupational exposure limits: a discussion of alternative methods. J Occup Environ Hyg 2006; 3: 501-507.

38 Gupta A, KD Rosenman. Hypersensitivity pneumonitis due to metal working fluids: sporadic or under reported? Am J Ind Med 2006; 49: 423-433.

39 Ross AS, Teschke K, Brauer M, et al. Determinants of exposure to metalworking fluid aerosol in small machine shops. Ann Occup Hyg 2004; 48: 383-391. 